Egyptian Journal of Aquatic Biology \& Fisheries

Zoology Department, Faculty of Science,

Ain Shams University, Cairo, Egypt.

ISSN $1110-6131$

Vol. 25(3): $421-434$ (2021)

www.ejabf.journals.ekb.eg

\title{
Evaluation of the larvicidal activity of nanoemulsion from Citrus aurantifolia (Christm) Swingle peel on Culex pipiens L. (Diptera: Culicidae) and the induced morphological aberrations
}

\author{
Radwa M. Azmy, El Gohary E. El Gohary, Dalia A. M. Salem, Dalia M. Mahmoud, \\ Mohamed S. Salama, and Mohamed A. Abdou* \\ Department of Entomology, Faculty of Science, Ain Shams University, Cairo, Egypt \\ *Corresponding Author: drmabdou@ @ sci.asu.edu.eg
}

\begin{abstract}
ARTICLE INFO
Article History:

Received: May 21, 2021

Accepted: June 2, 2021

Online: June 8, 2021

Keywords:

Nanoemulsion;

Essential oil;

Citrus aurantifolia;

Culex pipiens;

Larvicide;

Morphological

aberrations.

ABSTRACT

There is an urgent need for effective safe alternatives to chemical insecticides for the control of the insect vectors of diseases. Nanotechnology is a promising field for such innovative products. The current study was implemented to evaluate the toxicity of the nanoemulsion prepared from the essential oil (EO) of Cirtus aurantifolia peel against the third instar larvae of Culex pipiens and the morphological alterations in the larvae induced by the nanoemulsion. The formulated nanoemulsion was characterized; the mean droplet size was $20.7 \pm 2.6 \mathrm{~nm}$ with a polydispersity index value of 0.298. The $\mathrm{LC}_{\mathbf{5 0}}$ of the EO nanoemulsion was $33.65 \mathrm{ppm}$. The tested larvicide induced notable morphological aberration in the treated $C x$. pipiens larvae compared to the untreated ones; mainly in the anal region. The present research showed that nanoemulsion of $C$. aurantifolia EO can be used efficiently and ecofriendly in the integrated control programs of the vector-borne disease $C x$. pipiens larvae.
\end{abstract}

\section{INTRODUCTION}

Mosquito borne diseases are one of the world's most serious health problems. Culex pipiens was identified as a vector of Filariasis and some arboviruses including Rift Valley fever, encephalitis, Sindbis, and West Nile viruses. Cx. pipiens is incriminated as the filarial vector in Egypt (Dyab et al.,, 2015; El-Naggar $\boldsymbol{e t}$ al.,, 2017). The misuse of the chemical insecticides created many problems in the environment by leaving toxic residues (Bigoga et al., 2013; Bonner \& Alavanja, 2017). In addition, Mosquitoes have developed different levels of resistance against most available insecticides, such chemicals are non-biodegradable in nature causing decline in soil fertility and water pollution, and they are also harmful to non-target organisms (Sinha et al.,, 2004). All of these reasons stimulated a strong need to develop biodegradable and target-specific insecticides. Botanical insecticides are used conventionally in different countries around the world. Many essential oils (EOs) show effectiveness as larvicides against mosquito larvae (Amer \& Mehlhorn, 2006; Pitasawat et al.,, 2007; Knio et al.,, 2008) . Larvicides prepared from essential oil (EO) are presented as alternatives for industrial larvicides (Pavela, 2015; Govindarajan et al., 2018). Despite these promising properties 
of EOs, technological obstacles correlated to their poor water solubility, evaporation, and tendency to oxidation should be adjusted to prepare these compounds for proper alternative pest control system (Moretti et al., 2002). In order to retain biological activity of EO, vaporization of volatile constituents of EO has to be prevented. Nanoemulsion of the EO could solve the problem of water solubility. Ultrasonic emulsification is widely used method, it makes use of high frequency sound waves to cause intense shock waves which breaks the emulsion droplets into smaller ones (Behrend et al., 2000) . Nanoemulsions are oil in water submicron emulsions with droplet size 10:100 nm (Shafiq et al., 2007) with increased bioactivity, due to better diffusion and subcellular size (Esmaeili et al., 2016; Khani et al., 2016). Nanoemulsions are important formulations that enhance solubility of poorly water-soluble oils, producing stable formulations without use of toxic organic solvents. Citrus aurantifolia (christm) Swingle is ordinarily known as acid lime and belongs to Family Rutaceae. The peels are containing numerous oil glands (Apraj et al., 2011).

The main aim of the current study is to make use of Citrus aurantifolia (christm) Swingle peel as agricultural wastes along with the revolutionary nanotechnology to formulate a safe, eco-friendly and potent larvicide against $C x$. pipiens to be used in the programs of disease-vectors control.

\section{MATERIALS AND METHODS}

\section{Maintenance of Culex pipiens L. colony:}

Egg rafts were collected from a water body in Abu Rwash region, Giza governorate. The larvae were reared under controlled conditions; RH $70 \pm 10 \%$, temperature $\left(25 \pm 2{ }^{\circ} \mathrm{C}\right)$, and a photoperiod of 14:10 light/dark hours. The bioassay tests were performed on the fifth generation.

\section{Extraction of the essential oils (EO):}

Fresh fruits of Citrus aurantifolia were collected from Cairo, Egypt. Essential oil (EO) extraction from the peels of the fruits was done through Hydro-distillation, using a Clevenger-type apparatus according to Meyer-Warnod (1984).

\section{Nanoemulsion preparation:}

Bulk emulsion was prepared using the essential oil (EO), Tween 20 (Polyoxyethylene 20 sorbitan monolaurate) and distilled water according to (Duarte $\boldsymbol{e t}$ al., 2015). The bulk emulsion was subjected to a Sonicator (Ultrasonics, USA/ digital ultrasonic cleaner cd 4830) at frequency of $30 \mathrm{kHz}$ and power output $750 \mathrm{~W}$ for 30 minutes according to Anjali et al. (2012) .

\section{Characterization of the nanoemulsion of Citrus aurantifolia EO:}

Droplet Size Distribution \& Poly dispersity index (PDI): Dynamic light scattering (DLS) technique was used to measure the droplet size according to Sugumar et al. (2014) using particle size analyzer (Malvern-UK, 4700) in Egyptian Petroleum Research Institute (EPRI).

Stability: Thermodynamic stability of the Nanoemulstion was checked by storing it independently at $25^{\circ} \mathrm{C}$ and $4^{\circ} \mathrm{C}$ for a month. In addition, the nanoemulsion was observed 
for any phase separation, creaming, or cracking after centrifugation at $10,000 \mathrm{rpm}$ for 30 min according to (Ghosh et al., 2013).

\section{Bioassay tests:}

Bioassay was performed using third instar larvae of $C x$ pipiens kept at temperature $25 \pm 2^{\circ} \mathrm{C}$ and $75 \pm 5 \%$ relative humidity. The larvae were treated with different concentrations of nanoemulsion according to the standard World Health Organization protocol (WHO, 2005).

Five concentrations of the nanoemulsion 5, 15, 25, 35, and $40 \mathrm{ppm}$ were used. While for bulk emulsion 50, 100, 150, 250, and $300 \mathrm{ppm}$ were used. For each treatment, five replicates of twenty five larvae were used for each one.

For the control, the surfactant only was used at the same concentrations used for both nanoemulsion and bulk emulsion preparations. Mortality was recorded after 24 hours post treatment. Lethal concentrations were detected by using probit analysis at the 95\% confidence level. For each concentration of the EO nanoemulsion, the mean percentages of larval mortality were calculated.

\section{Morphological observations:}

Larvae treated with the $\mathrm{LC}_{50}$ of EO nanoemulsion were observed after 24 hours to record any morphological aberrations compared to the control ones. Morphological observations were examined by a Leica EZ4 HD microscope equipped with a camera (3.0 Mega-Pixel CMOS).

\section{Ultrastructural study:}

The investigation was finished utilizing a JEOL transmission electron microscope (TEM) JEM1011, at the Regional Center of Mycology and Biotechnology (RCMB), AlAzhar University. The untreated and treated larvae with the nanoemulsion of the essential oil and EO disintegrated in the $100 \%$ ethanol were fixed in 5\% glutaraldehyde and afterward washed in alcohol (70\%) as indicated by Disbrey (1970). A buffer of 0.1-M sodium cacodylate was used for samples preparation at room temperature for four hours at $\mathrm{pH}$ 7.2. Samples then washed twice in 0.1-M cacodylate buffer for $15 \mathrm{~min}$. Samples drenched in $1 \%$ osmium tetroxide dissolved in $0.1-\mathrm{M}$ sodium cacodylate buffer for two hours, at that point washed in 0.1-M cacodylate buffer three multiple times, $15 \mathrm{~min}$ for each. Samples were then submerged and dehydrated in graded sequences of ethanol. Dehydrated samples were embedded in epoxy resin. Ultrathin sections (50-80 nm thick) were cut by utilizing glass blades. Sections were stained in uranyl acetate stain then lead citrate stain according to Reynolds (1963).

\section{Statistical analysis:}

Biological data were expressed as mean \pm SE. Data between treated groups were analyzed using SPSS software; the level of significance was tested using one way analysis of variance (ANOVA). The data was considered statistically significant when $P$ $<0.05$. 


\section{RESULTS}

\section{Extraction of the essential oil EO:}

The extracted EO from Citrus aurantifolia was found to be transparent slightly greenish in color and has an aromatic odor characteristic of lime.

\section{Characterization of the formulated EO nanoemulsion:}

The formulated EO nanoemulsions of $C$. aurantifolia was milky slightly greenish in color.

\section{Droplet size and Poly dispersity index (PDI):}

The droplet size distribution of the EO nanoemulsion was less than $30 \mathrm{~nm}$ (Figure 1), with the peak at $16.11 \mathrm{~nm}$ and the mean droplet diameter of the EO nanoemulsion was calculated to be $2.67 \pm 2.6 \mathrm{~nm}$. The value of the PDI was equal to 0.298 (Figure 2).

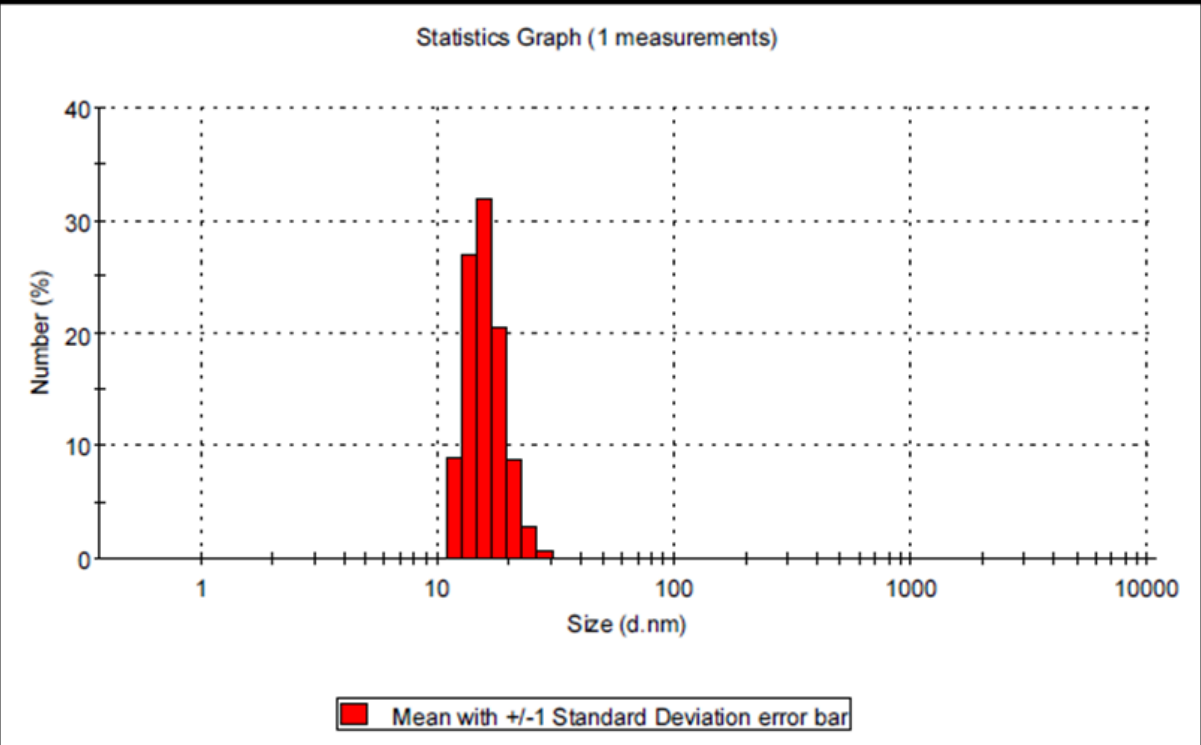

Figure 1. Droplet size distribution of the EO nanoemulsion droplets of Citrus aurantifolia by DLS.

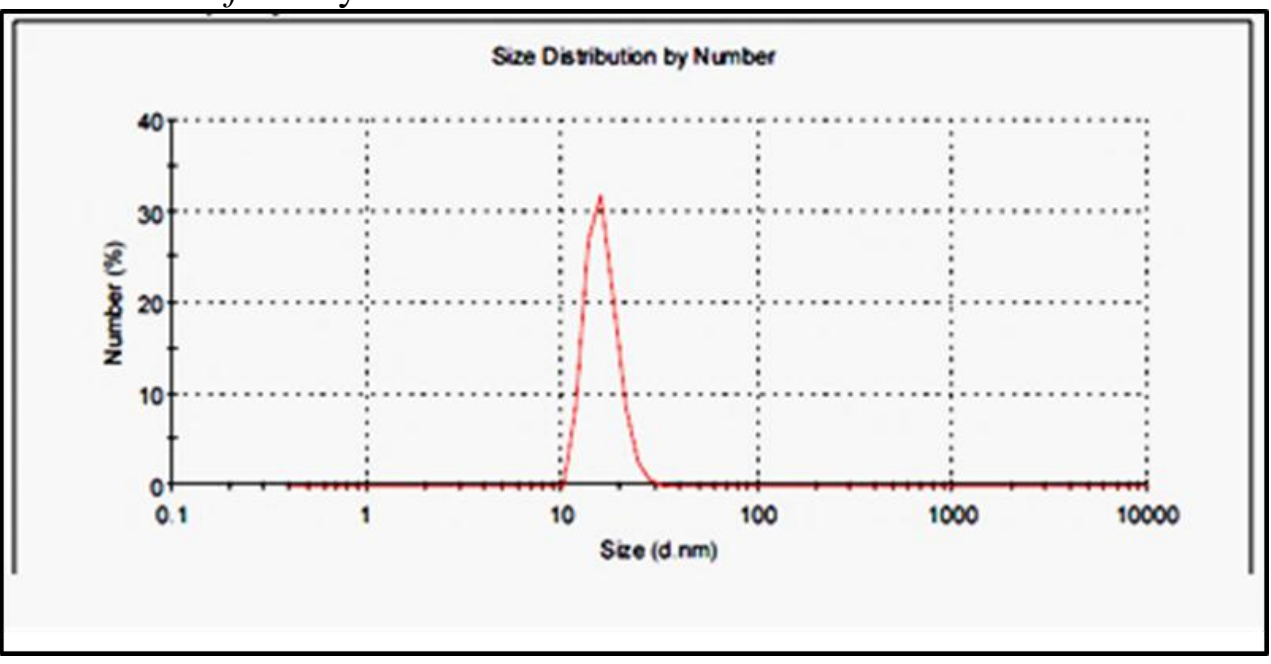

Figure 2. Droplet size distribution of Citrus aurantifolia EO nanoemulsion with the peak at $16.11 \mathrm{~nm}$. 
The droplet size distribution of the essential oil (EO) as bulk emulsion of $C$. aurantifolia was found to have a peak at $1564 \mathrm{~nm}$ which represents the most common droplet size. The value of the PDI is equal to 0.684

\section{Stability of EO nanoemulsion:}

There was no observed sign of instability of the EO nanoemulsion, neither phase separation nor creaming, it was stable after centrifugation for $30 \mathrm{~min}$ at 10,000 rpm and also stable when stored for a month at $4^{\circ} \mathrm{C}$.

\section{Bioassay tests:}

The toxic effect of the EO nanoemulsion on the third instar larvae was significantly increased $(P<0.05)$ with the increase of concentration. There were concentrationdependent significant correlations of the EO nanoemulsion with larval mortality as resulted from the Regression analysis. The mortality percentages of the treated larvae caused by EO nanoemulsion and bulk emulsion were presented (Table 1).

Table 1. Mean mortality percentages of $3^{\text {rd }}$ instar Culex pipiens larvae treated with the EO nanoemulsion and the EO bulk emulsion of Citrus aurantifolia after $24 \mathrm{hrs}$ post treatment.

\begin{tabular}{|l|l|l|l|}
\hline \multicolumn{2}{|c|}{ EO nanoemulsiom } & \multicolumn{2}{c|}{ EO bulk emulsion } \\
\hline $\begin{array}{l}\text { Conc. } \\
\text { ppm }\end{array}$ & $\begin{array}{l}\text { Mortality } \\
\text { Percentages } \\
(\text { Mean } \pm \text { SE) }\end{array}$ & $\begin{array}{l}\text { Conc. } \\
\text { ppm }\end{array}$ & $\begin{array}{l}\text { Mortality } \\
\text { Percentages } \\
(\text { Mean } \pm S E)\end{array}$ \\
\hline - ve control & $0 \pm 0 \mathrm{a}$ & - ve control & $0 \pm 0 \mathrm{a}$ \\
\hline+ ve control & $0 \pm 0 \mathrm{a}$ & + ve control & $0 \pm 0 \mathrm{a}$ \\
\hline 25 & $20 \pm 2.3 \mathrm{~b}$ & 100 & $24 \pm 0.5 \mathrm{~b}$ \\
\hline 30 & $45 \pm 0.8 \mathrm{c}$ & 150 & $28 \pm 9.5 \mathrm{c}$ \\
\hline 35 & $58 \pm 1.1 \mathrm{~d}$ & 200 & $52 \pm 1.2 \mathrm{~d}$ \\
\hline 40 & $61 \pm 0.5 \mathrm{e}$ & 250 & $65 \pm 3.5 \mathrm{e}$ \\
\hline 45 & $71 \pm 0.8 \mathrm{f}$ & 300 & $81.7 \pm 1 \mathrm{f}$ \\
\hline
\end{tabular}

Means bearing different letters within a column are significantly different $(P<0.05)$ ANOVA, LSD test. 


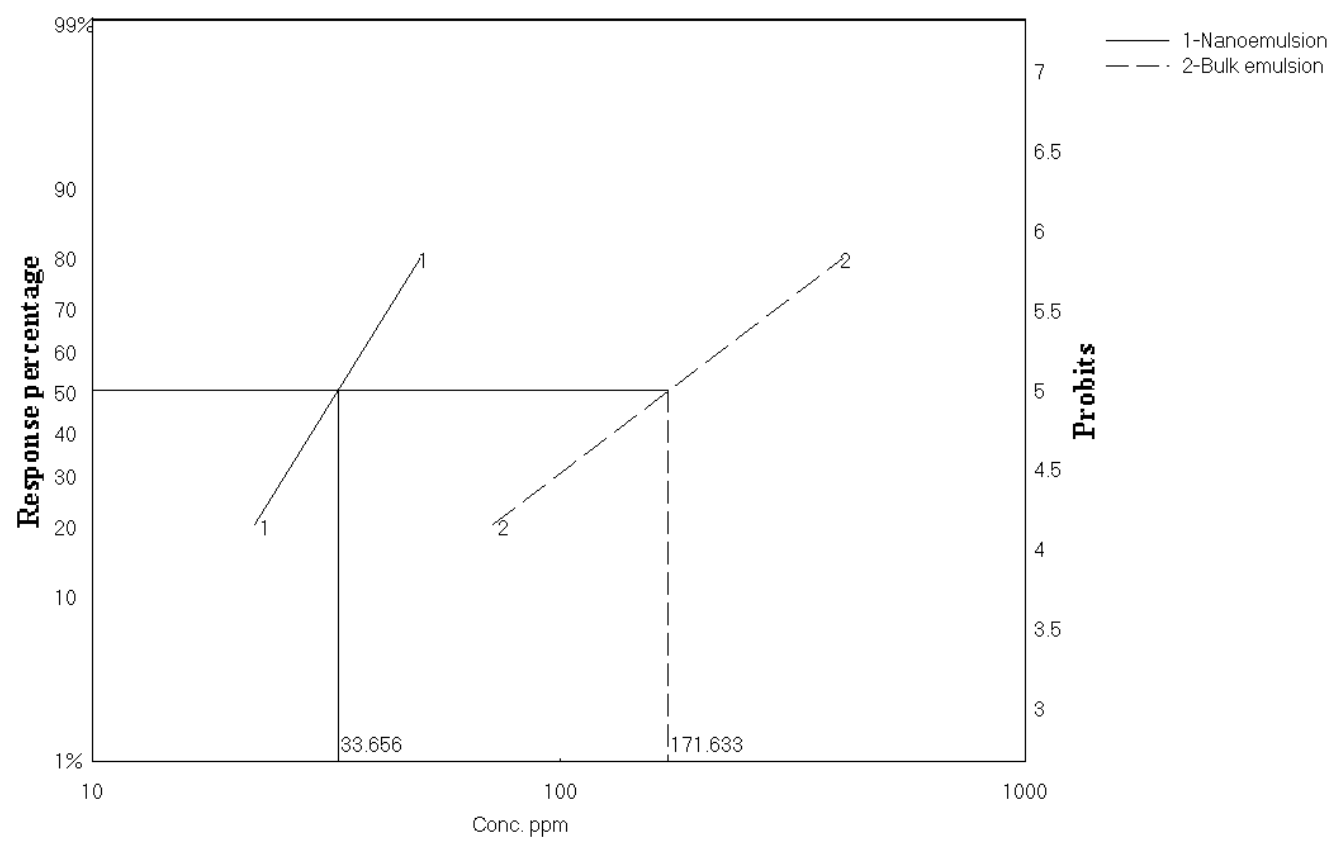

Figure 3. Regression line of probit mortality of Culex pipiens larvae against the log concentrations of the nanoemulsion and bulk emulsion of Citrus aurantifolia essential oil.

The $\mathrm{LC}_{25}$ and the $\mathrm{LC}_{50}$ values of EO nanoemulsion were estimated to be 24.25 and 33.65 ppm, for the EO bulk emulsion, the same values were 85.87 and $171.63 \mathrm{ppm}$, respectively (Figures $3 \& 4$ ). The EO nanoemulsion is more efficient than the EO bulk emulsion according to the $\mathrm{LC}_{50}$ and $\mathrm{LC}_{25}$ values (Figure 4 ).

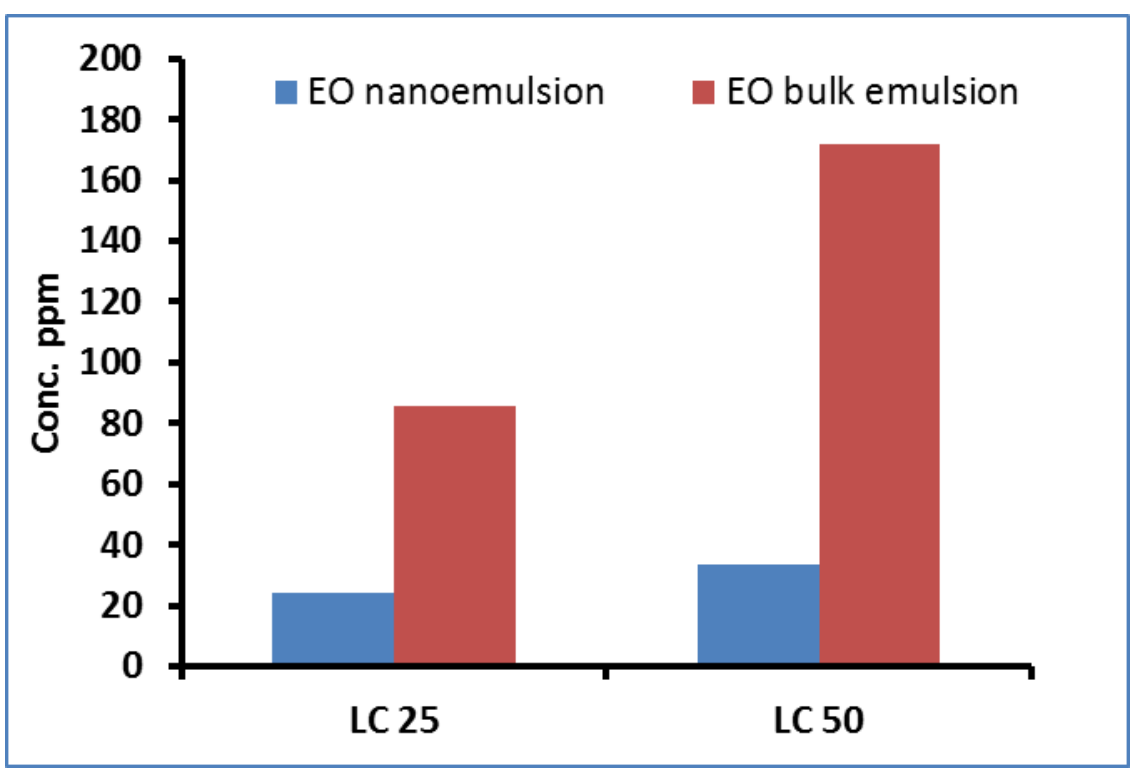

Figure 4. $\mathrm{LC}_{25}$ and $\mathrm{LC}_{50}$ of $\mathrm{EO}$ nanoemulsion and $\mathrm{EO}$ bulk emulsion of Citrus aurantifolia against $3^{\text {rd }}$ instar Culex pipiens larvae after $24 \mathrm{hrs}$. 


\section{Morphological observations:}

The anal papillae of the treated larvae showed abnormal pigmentation and shrinkage whereas the external features of papillae were found to be normal as observed in the control larvae. The treated larvae with $\mathrm{LC}_{50}$ of the nanoemulsions of $C$. aurantifolia $\mathrm{EO}$ exhibited morphological aberrations when compared to the control larvae (Figure 5A) such as damaged and distorted anal papillae, darkening and abnormal swollen in anal segment, and also darken and hardened anal papillae. In addition to the distinguished hard open rose-like papillae (Figure 5B-F).
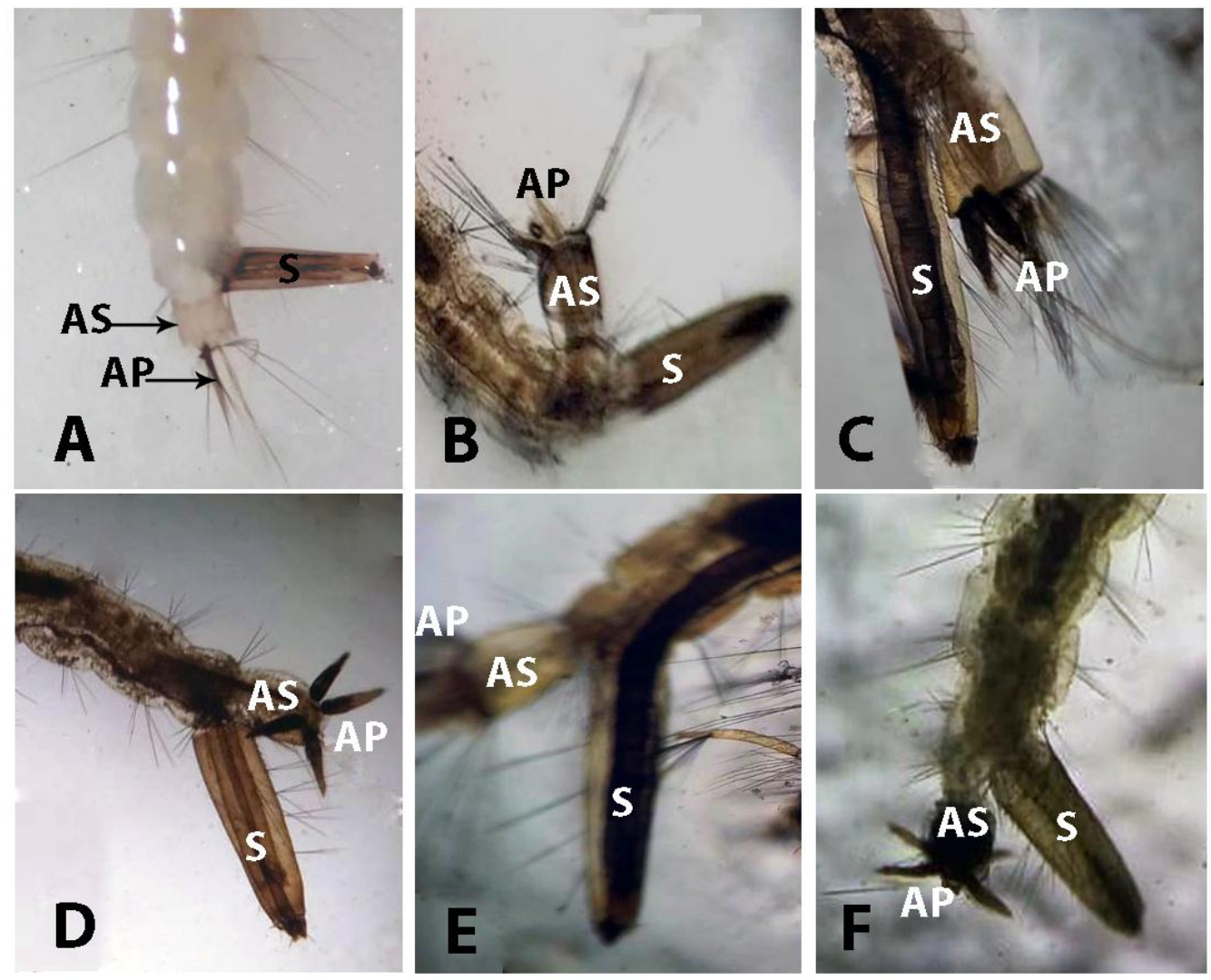

Figure 5. Photomicrographs of the terminal segment of the 3rd instar larvae of Culex pipiens $(10 \times)$. (A) The control larva; (B-F) Larvae treated with $\mathrm{LC}_{50}$ of the $\mathrm{EO}$ nanoemulsion of Citrus aurantifolia. AS: anal segment; S: siphon; AP: anal papillae.

\section{Ultrastructural Changes in skeletal muscles:}

The skeletal muscles in normal larvae comprise of the contractile striated fibers lying corresponding and parallel to one another; each fiber comprises of numerous parallel fibrillae in the sarcoplasm. The longitudinal muscle fibers are sheathed by a connectivetissue layer; the structure of myofibrils shows the presence of thick cylindrical filaments (myosin) and fine filaments (actin). The untreated larvae demonstrated well-organized myofibrils (f) with densely distributed myofilaments (actin and myosin) which are surrounded by sarcoplasmic reticulum (sr) (Figure 6A). The larvae treated with the EO nanoemulsion showed vacuolization and disorganization of fibrils (Figure 6B-D). 

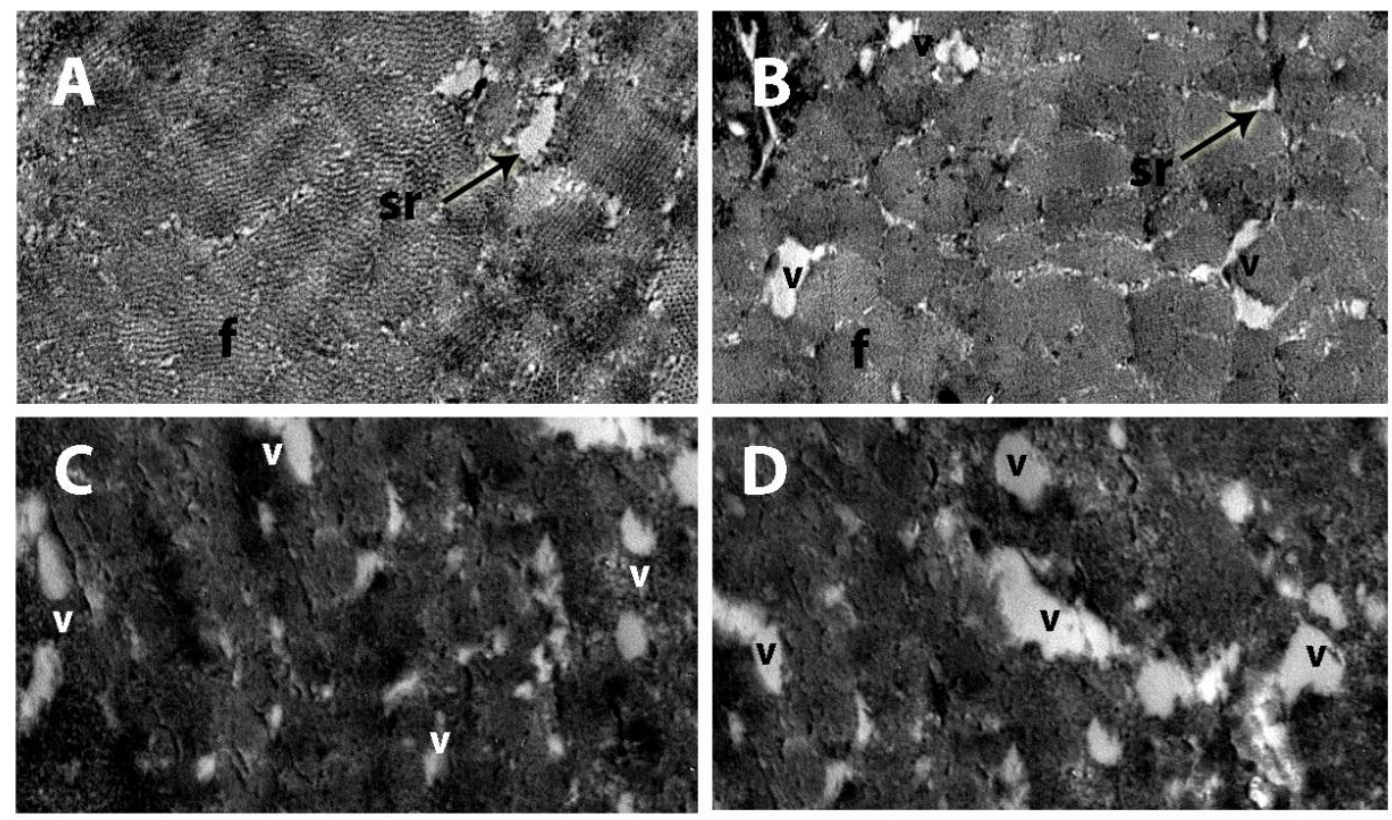

Figure 6. TEM microphotograph of cross-sectioned skeletal muscle fibrils of larvae of Culex pipiens: (A) the control larvae (20000x); (B-D) larvae treated with EO nanoemulsion of Citrus aurantifolia (12000x). (f) fibril, (sr) sarcoplasmic reticulum, (v) vacuole.

\section{DISCUSSION}

The use of nanoemulsions of EOs to control mosquitoes is considered safe to the environment as compared to synthetic pesticides. The worldwide inclination of phytochemicals in disease vector control might be founded on their exceptional properties which incorporate ecological supportability, effectively biodegradable, promptly accessible, modest and non-poisonousness to man and his homegrown creatures (Bakkali et al., 2008) .

Mosquitoes in the larval stage are appealing focuses for pesticides since they breed in water and it is not difficult to manage them in this environment (Amer \& Mehlhorn, 2006), thus, the active substances must be dispersed in their aquatic medium. The toxicity of the EOs increases when working through oral way and integumentary dissemination (Akono et al., 2015).

Characterization of the prepared Nano emulsion of Citrus aurantifolia EO in this study showed that the mean droplet size was less than $100 \mathrm{~nm}$, which means that it was within the nano-range according to McClements (2011). The diminished size and uniform spreading of these fine particles expanded the larvicidal activity according to Anjali et al. (2012).

The alluring powers between the droplets is corresponding to the size of the droplets thus when the size of the droplets are in the nano range, the alluring powers between the droplets are frail, consequently, forestalling molecule accumulation and helps in creation the nanoemulsions more steady (McClements, 2011). The low PDI of the nanoemulsions indicates the good stability and homogenity of the nanoemulsion according to Hoeller $\boldsymbol{e t}$ 
al. (2009) and Shakeel et al. (2007). The stabilization of the nanoemulsion is due to the surfactant, as it provides a mechanical barrier to prevent accumulation.

The higher efficiency of the nanoemulsion than the bulk emulsion may be due to the smaller size of the nanoemulsion droplets, which increases the surface area and facilitates the penetration of nanoemulsion into the larvae according to Anjali et al. (2012). the results agreed with that presented by several studies as Sugumar et al. (2014) who reported that the nanoemulsion of the eucalyptus oil and castor oil were more efficient than their bulk counterpart. Sogan et al. (2018) reported that the nanoemulsion of the castor oil was more efficient than its bulk emulsion. While, Azmy et al. (2019) reported that nanoemulsion of Citrus sinensis EO was more efficient than its bulk emulsion against larvae of Culex pipiens.

Larvicidal activity of the EO nano emulsion may be due to its major component (limonene) which was reported to have insecticidal property according to Saad (2013). Our outcomes concur with some examinations on the nanoemulsions dependent on EOs as compelling insecticides (Anjali et al., 2012; Ghosh et al., 2013; Sugumar et al., 2014; Duarte et al., 2015). The botanical molecules are able to interact with body hormones, enzymes and bind to membranes and cellular components and thus interfere with biochemical pathways of the mosquito (Fallatah, 2010; Powell, 2009).

Monoterpenes are working on the nervous system (neurotoxicants) in diverse insect species (Coats, 1990), they have been appeared to repress acetylcholinesterase (AChE) (Grundy \& Still, 1985; Ryan \& Byrne, 1988). Accordingly, they cause a severe decrease in the Golgi bodies' number and intact mitochondria, impairing respiration and decreasing cell membrane permeability (Tripathi et al., 2009).

Akono et al. (2015) suggested that limonene could act synergistically with other minor compounds such as $\alpha$-pinene and $\beta$-pinene to increase the potential toxicity of EOs. The insecticidal activity of these molecules has been demonstrated by Lucia et al. (2007) and Ojimelukwe \& Adler (1999).

The morphological observations of the present study indicated that the anal region was the common place of aberrations; the aberrations included darkening and deformation of the siphon, anal segment and papillae along with the distinct rose-like shape of the anal segment. Equally, the mosquito larvae treated with seaweed extract were seen to show similar way of deviations and aberrations on the anal which contribute to the death of larvae as reported by Yu et $\boldsymbol{a l}$. (2015). Also the anal papillae and respiratory siphon of Aedes aegypti larvae were affected when Dalarmi et al. (2015) treated the larvae with fractions of Dalbergia brasiliensis extracts as a potential larvicide.

The deformation of larval anal segment recorded in the present study is recommended to make obliteration the hydrophobic surface of anal segment, driving encompassing water to enter the tracheal trunk and induce damages to the respiratory system in the larvae which cause suffocation and drowning of the larvae (Kumar et al., 2010; Bianco et al., 2013). It has been proposed that the structural deformity in the anal papillae conceivably led to anomalous functions which may cause the disturbance in osmotic and ionic regulation (Chaithong et al., 2006; Rocha et al., 2015; Azmy et al., 2020) . Penetration through cuticle is important for insecticidal activity and recognized as one of the possible mechanisms of insecticides.

The treated third instar larvae with the $\mathrm{LC}_{50}$ of the nanoemulsion of $C$. aurantifolia $\mathrm{EO}$ showed disorganization of fibrils, vacuolization, and occurrence of fissures in the 
muscles. The obtained results resemble those commonly demonstrated in insect response to toxic substances such as the Myrrh extracts on mosquito larvae (Al-Mehmadi \& AlKhalaf, 2010). The abnormal muscle formation and the morphogenetic effects probably result from the active chemical compounds. We suggest that the aberration in the skeletal muscles affected the movement of the larvae lead to failure of move up and down to breath and finally drowning of the larvae.

\section{CONCLUSION}

To our knowledge, this is the first record that a nanoemulsion of the EO extracted from the agricultural waste of Citrus aurantifolia peels is reported as a potent larvicide against Culex pipiens, and it can be contributed to the integrated management programs. Based on the $\mathrm{LC}_{50}$ values, the nanoemulsions of $C$. aurantifolia EO showed higher toxicity against $C x$. pipiens larvae than the bulk emulsions of the EO. The small size of droplets $(<100 \mathrm{~nm})$ may be the most effective factor in the efficiency of the nanoemulsion in controlling mosquito larvae compared to droplets $(>1000 \mathrm{~nm})$ of the bulk emulsion. The findings of the present investigation revealed that $C$. aurantifolia $\mathrm{EO}$ has a larvicidal effect which is concentration-dependent against the $C x$. pipiens larvae. It's also exhibited morphological aberrations in the anal segment and ultrastructural alterations represented in muscle damage.

The consequences of this examination will add to an incredible decrease in the utilization of synthetic insecticides, which thus decline the environmental contamination. Likewise, the current investigation may energize further exploration on utilizing straightforward and economical application strategies for controlling mosquitoes in their breeding locations.

\section{REFERENCES}

Akono, P.; Dongmo, P.; Tonga, C.; Kouotou, S.; Kekeunou, S.; Magne, G.; Lehman, L. and Menut, C. (2015). Larvicidal activity of essential oils from pericarps of ripe Citrus fruits cultivated in Cameroon on pyrethroids sensitive and resistant strains of Anopheles gambiae Giles, 1902. J Entomol Zool Studies, 3: 334-339.

Al-Mehmadi, R. and Al-Khalaf, A. (2010). Larvicidal and histological effects of Melia azedarach extract on Culex quinquefasciatus Say larvae (Diptera: Culicidae). Journal of King Saud University-Science, 22(2): 77-85.

Amer, A. and Mehlhorn, H. (2006). Repellency effect of forty-one essential oils against Aedes, Anopheles, and Culex mosquitoes. Parasitology Research, 99(4): 478-490.

Anjali, C.; Sharma, Y.; Mukherjee, A. and Chandrasekaran, N. (2012). Neem oil (Azadirachta indica) nanoemulsion - a potent larvicidal agent against Culex quinquefasciatus. Pest Management Science, 68(2): 158-163.

Apraj, V.; Thakur, N.; Bhagwat, A.; Mallya, R.; Sawant, L. and Pandita, N. (2011). Pharmacognostic and phytochemical evaluation of Citrus aurantifolia (Christm) Swingle peel. Pharmacognosy Journal, 3(26): 70-76. 
Azmy, R.; El Gohary, E.; Mahmoud, D.; Salem, D.; Abdou, M. and Salama, M. (2019). Assessment of larvicidal activity of nanoemulsion from Citrus sinensis essential oil on Culex pipiens L.(Diptera: Culicidae). Egypt. J. Aquat. Biol. Fish, 23(3): 61-67.

Azmy, R.; El Gohary, E.; Salem, D.; Abdou, M.; Salama, M. and Mahmoud, D. (2020). Biochemical and histopathological effect of the essential oil of Citrus sinensis (L.) Osbeck on larvae of Culex pipiens Linnaeus, 1758 (Diptera: Culicidae). Aquatic Insects, 42 (1): 78-90.

Bakkali, F.; Averbeck, S.; Averbeck, D. and Idaomar, M. (2008). Biological effects of essential oils-a review. Food and Chemical Toxicology, 46(2): 446-475.

Behrend, O. and Schubert, H. (2000). Influence of continuous phase viscosity on emulsification by ultrasound. Ultrasonics Sonochemistry, 7(2): 77-85.

Bianco, E.; Pires, L.; Santos, G.; Dutra, K.; Reis, T.; Vasconcelos, E.; Cocentino, A. and Navarro, D. (2013). Larvicidal activity of seaweeds from northeastern Brazil and of a halogenated sesquiterpene against the dengue mosquito (Aedes aegypti). Industrial Crops and Products, 43: 270-275.

Bigoga, J.; Saahkem, P.; Ndindeng, S.; Ngondi, J.; Nyegue, M.; Oben, J. and Leke, R. (2013). Larvicidal and repellent potential of Chenopodium ambrosioides Linn essential oil against Anopheles gambiae Giles (Diptera: Culicidae). The Open Entomology Journal, 7(1): 16 - 22.

Bonner, M. and Alavanja, M. (2017). Pesticides, human health, and food security. Wiley Online Library.

Chaithong, U.; Choochote, W.; Kamsuk, K.; Jitpakdi, A.; Tippawangkosol, P.; Chaiyasit, D.; Champakaew, D.; Tuetun, B. and Pitasawat, B. (2006). Larvicidal effect of pepper plants on Aedes aegypti (L.) (Diptera: Culicidae). Journal of Vector Ecology, 31(1): 138-144.

Coats, J. (1990). Mechanisms of toxic action and structure-activity relationships for organochlorine and synthetic pyrethroid insecticides. Environmental Health Perspectives, 87: $255-262$.

Dalarmi, L.; da Silva, C.; Ocampos, F.; Burci, L.; do Nascimento, K.; de Jesus, C.; Dias, J.; Miguel, M.; Miguel, O. and Zanin, S. (2015). Larvicidal activity of Dalbergia brasiliensis (Fabaceae-Papilionoideae) on Aedes aegypti. African Journal of Pharmacy and Pharmacology, 9(35): 881-885.

Disbrey, B. (1970). Histological Laboratory Methods. E. \& S. Livingstone, Edinburgh and London, 140-145.

Duarte, J.; Amado, J.; Oliveira, A.; Cruz, R.; Ferreira, A.; Souto, R.; Falcão, D.; Carvalho, J. and Fernandes, C. (2015). Evaluation of larvicidal activity of a nanoemulsion of Rosmarinus officinalis essential oil. Revista Brasileira de Farmacognosia, 25(2): 189-192.

Dyab, A.; Galal, L.; Mahmoud, A. and Mokhtar, Y. (2015). Xenomonitoring of different filarial nematodes using single and multiplex PCR in mosquitoes from Assiut Governorate, Egypt. The Korean Journal of Parasitology, 53(1): 77. 
El-Naggar, A.; Elbanna, S.; Kaiser, M. and Gabre, R. (2017). Mosquito larval habitat mapping using remote sensing and GIS for monitoring the filarial infection regions in Alkorin village, Sharkia Governorate (Egypt). Int J Mosq Res, 4(4): 135-139.

Esmaeili, F.; Rajabnejhad, S.; Partoazar, A.; Mehr, S.; Faridi-Majidi, R.; Sahebgharani, M.; Syedmoradi, L.; Rajabnejhad, M. and Amani, A. (2016). Antiinflammatory effects of eugenol nanoemulsion as a topical delivery system. Pharmaceutical Development and Technology, 21(7): 887-893.

Fallatah, S. (2010). Histopathological effects of fenugreek (Trigonella foenumgraceum) extracts on the larvae of the mosquito Culex quinquefasciatus. J. Arab Soc. Med. Res, 5(2): 123-130.

Ghosh, V.; Mukherjee, A. and Chandrasekaran, N. (2013). Formulation and characterization of plant essential oil based nanoemulsion: evaluation of its larvicidal activity against Aedes aegypti. Asian Journal of Chemistry, 25(Supplementary Issue), S321.

Govindarajan, M.; Rajeswary, M.; Senthilmurugan, S.; Vijayan, P.; Alharbi, N.; Kadaikunnan, S.; Khaled, J. and Benelli, G. (2018). Curzerene, trans- $\beta$-elemenone, and $\gamma$-elemene as effective larvicides against Anopheles subpictus, Aedes albopictus, and Culex tritaeniorhynchus: toxicity on non-target aquatic predators. Environmental Science and Pollution Research, 25(11): 10272-10282.

Grundy, D. and Still, C. (1985). Inhibition of acetylcholinesterases by pulegone-1, 2epoxide. Pesticide Biochemistry and Physiology, 23(3): 383-388.

Hoeller, S.; Sperger, A. and Valenta, C. (2009). Lecithin based nanoemulsions: A comparative study of the influence of non-ionic surfactants and the cationic phytosphingosine on physicochemical behaviour and skin permeation. International Journal of Pharmaceutics, 370(1-2): 181-186.

Khani, S.; Keyhanfar, F. and Amani, A. (2016). Design and evaluation of oral nanoemulsion drug delivery system of mebudipine. Drug Delivery, 23(6): 2035-2043.

Knio, K.; Usta, J.; Dagher, S.; Zournajian, H. and Kreydiyyeh, S. (2008). Larvicidal activity of essential oils extracted from commonly used herbs in Lebanon against the seaside mosquito, Ochlerotatus caspius. Bioresource Technology, 99(4): 763-768.

Kumar, S.; Warikoo, R. and Wahab, N. (2010). Larvicidal potential of ethanolic extracts of dried fruits of three species of peppercorns against different instars of an Indian strain of dengue fever mosquito, Aedes aegypti L. (Diptera: Culicidae). Parasitology Research, 107(4): 901-907.

Lucia, A.; Audino, P.; Seccacini, E.; Licastro, S.; Zerba, E. and Masuh, H. (2007). Larvicidal effect of Eucalyptus grandis essential oil and turpentine and their major components on Aedes aegypti larvae. Journal of the American Mosquito Control Association, 23(3): 299-303.

McClements, D. (2011). Edible nanoemulsions: fabrication, properties, and functional performance. Soft Matter, 7(6): 2297-2316. 
Meyer-Warnod, B. (1984). Natural essential oils: extraction processes and application to some major oils. Perfumer \& Flavorist, 9(2): 93-104.

Moretti, M.; Sanna-Passino, G.; Demontis, S. and Bazzoni, E. (2002). Essential oil formulations useful as a new tool for insect pest control. AAPs PharmSciTech, 3(2): 6474.

Ojimelukwe, P. and Adler, C. (1999). Potential of zimtaldehyde, 4-allyl-anisol, linalool, terpineol and other phytochemicals for the control of the confused flour beetle (Tribolium confusum J. d. V.) (Col., Tenebrionidae). Anzeiger Für Schädlingskunde. Journal of Pest Science, 72(4): 81-86.

Pavela, R. (2015). Essential oils for the development of eco-friendly mosquito larvicides: a review. Industrial Crops and Products, 76: 174-187.

Pitasawat, B.; Champakaew, D.; Choochote, W.; Jitpakdi, A.; Chaithong, U.; Kanjanapothi, D.; Rattanachanpichai, E.; Tippawangkosol, P.; Riyong, D. and Tuetun, B. (2007). Aromatic plant-derived essential oil: an alternative larvicide for mosquito control. Fitoterapia, 78(3): 205-210.

Powell, R. (2009). Plant seeds as sources of potential industrial chemicals, pharmaceuticals, and pest control agents. Journal of Natural Products, 72(3): 516-523.

Reynolds, E. (1963). The use of lead citrate at high $\mathrm{pH}$ as an electron-opaque stain in electron microscopy. Journal of Cell Biology, 17(1): 208-212.

Rocha, D.; Matos, O.; Novo, M.; Figueiredo, A.; Delgado, M. and Moiteiro, C. (2015). Larvicidal activity against Aedes aegypti of Foeniculum vulgare essential oils from Portugal and Cape Verde. Natural Product Communications, 10(4): 1934578 X1501000438.

Ryan, M. and Byrne, O. (1988). Plant-insect coevolution and inhibition of acetylcholinesterase. Journal of Chemical Ecology, 14(10): 1965-1975.

Saad, M. (2013). Chemical composition and biological activities of four Citrus essential oils. Journal of Plant Protection and Pathology, 4(9): 767-780.

Shafiq, S.; Shakeel, F.; Talegaonkar, S.; Ahmad, F.; Khar, R. and Ali, M. (2007). Design and development of oral oil in water ramipril nanoemulsion formulation: in vitro and in vivo assessment. Journal of Biomedical Nanotechnology, 3(1): 28-44.

Shakeel, F.; Baboota, S.; Ahuja, A.; Ali, J.; Aqil, M. and Shafiq, S. (2007). Nanoemulsions as vehicles for transdermal delivery of aceclofenac. Aaps Pharmscitech, 8(4): 191-199.

Sinha, C.; Agrawal, A.; Islam, F.; Seth, K.; Chaturvedi, R.; Shukla, S. and Seth, P. (2004). Mosquito repellent (pyrethroid-based) induced dysfunction of blood-brain barrier permeability in developing brain. International Journal of Developmental Neuroscience, 22(1): 31-37.

Sogan, N.; Kapoor, N.; Kala, S.; Patanjali, P.; Nagpal, B.; Vikram, K. and Valecha, N. (2018). Larvicidal activity of castor oil Nanoemulsion against malaria vector Anopheles culicifacies. Int J Mosq Res, 5(3): 1-6. 
Sugumar, S.; Clarke, S.; Nirmala, M; Tyagi, B; Mukherjee, A. and Chandrasekaran, N. (2014). Nanoemulsion of eucalyptus oil and its larvicidal activity against Culex quinquefasciatus. Bulletin of Entomological Research, 104(3): 393-402.

Tripathi, A.; Upadhyay, S.; Bhuiyan, M. and Bhattacharya, P. (2009). A review on prospects of essential oils as biopesticide in insect-pest management. Journal of Pharmacognosy and Phytotherapy, 1(5): 52-63.

WHO (2005). Guidelines for laboratory and field testing of mosquito larvicides. World Health Organization.

Yu, K.; Wong, C.; Ahmad, R. and Jantan, I. (2015). Larvicidal activity, inhibition effect on development, histopathological alteration and morphological aberration induced by seaweed extracts in Aedes aegypti (Diptera: Culicidae). Asian Pacific Journal of Tropical Medicine, 8(12): 1006-1012. 